Egypt. Acad. J. biolog. Sci., 3 (1): 19- 26 (2011)

Email: egyptianacademic@yahoo.com

Received: 28/7/2011
F. Toxicology \&Pest control

ISSN: 2090 - 0791

www.eajbs.eg.net

\title{
Effect of pesticides mixture of dimethoate and methidathion on acetylcholinestrase during embryo development using chick embryo model
}

\author{
Mohammed Ahssan Alhifi
}

Assistant Prof. of Environmental Studies, Sana'a University, Yemen. alhifi@yahoo.com

\begin{abstract}
Pesticides mixture (dimethoate 30\% and methidathion 40\%) prepared by the farmers in Yemen and engaged in the cultivation of Qat, which is chewed by people every day including pregnant women. Therefore, the developing embryos in the society are more vulnerable than adults to the chronic cholinergic intoxication. This study aimed to examine the chronic effect of pesticides mixture on the AChE of developmental embryo in an avian model, which does not share the maternal potential confounds. For this, fresh fertile chicken eggs (Gallus gallus domesticus) were used. The lethal concentration of pesticides mixture for $50 \%$ killing $\left(\mathrm{LD}_{50}\right)$ values was computed on the basis of probit analysis and was found to be $40 \mathrm{ppm} .1 / 5^{\text {th }} \mathrm{LD}_{50}$ and $1 / 10^{\text {th }} \mathrm{LD}_{50}$ (8 and $4 \mathrm{ppm}$ ) were chosen to be the tested doses. Eggs weighing $54 \pm 1$ gm were separated in to 3 batches of 10 eggs each batch. One batch of embryos was injected with normal saline and the other batches of embryos injected with pesticides mixture of 4 and $8 \mathrm{ppm}$ each alternative day starting from incubation day 7 for 2 weeks. On day 21 after 12 hours of the last dose an amount of $200 \mu$ l blood was collected from the blood vessels surrounding the embryonic membranes and the heamolyzate was used for the assessment of the AChE activity calorimetrically. Result of this study indicated that $1 / 10^{\text {th }}$ of the $\mathrm{LD}_{50}$ had only marginal effect on the AChE activity $(40.6 \%)$. Whereas $1 / 5^{\text {th }}$ of the $\mathrm{LD}_{50}$ of pesticides mixture caused significant inhibition of AChE activity (69\%) which could not be reversible. So neuro-developmental consequences such as behavioral changes and memory impairment may prolong throughout the life span of the embryo.
\end{abstract}

Key words: embryo, pesticide mixture, AChE.

\section{INTRODUCTION}

Insect pest management is facing the health and ecological challenge worldwide due to the human and environmental hazards caused by majority of the synthetic pesticide chemicals. Although beneficial in protecting the crop against insect pests, these pesticides have posed a grave environmental problem because of their indiscriminate use in fields. The organophosphorus insecticides (OPIs) are one of the most widely used and consequently their propensity to produce developmental neurotoxicity remains a major concern, (Colborn T, 2006, Costa LG, 2006, Landrigan PJ et al, 1999 and
Weiss B et al, 2004). Because pregnant womens are likely to be exposed to OPIs under circumstances that do not elicit outward signs of intoxication (De Peyster et al. 1993; Gurunathan et al. 1998) and in light of recent findings that such exposures can produce long term cognitive impairment in their children (Rauh et al. 2006; Rohlman et al. 2005), the mechanisms and consequences of OPIs developmental neurotoxicity remain a major environmental concern. The OPIs are known to affect the nervous system by inhibiting acetylcholinesterase (AChE), the enzyme that modulates the amount of the neurotransmitter acetylcholine (Fukuto, 1971). The inhibition of 
AChE results in the accumulation of acetylcholine that over stimulates cholinergic receptors, which in turn stimulates neurological activity, (Gallo and Lawryk, 1991). Indeed, a number of studies utilizing neural cell lines or micromass cultures have clearly demonstrated direct effects of organophosphates on neurodevelopment, (Bagchi D et al. 1995, Bagchi D et al. 2006, Crumpton TL et al. 2000, Das KP et al. 1999, Jameson RR et al. 2006, Monnet-Tschudi F et al. 2000, Qiao D et al. 2001, Qiao D et al. 2005, Slotkin TA et al. 2007 and Song X et al. 1998).

Unfortunately, people are often exposed to different OPIs in different dosages at different or overlapping times. However, the developing embryos remain more vulnerable than adults do to chronic cholinergic intoxication by OPIs. These agents affect the process of neural development itself, leading to permanent deficits in the architecture of the nervous system.

Despite the increasing recognition of the need to evaluate developmental neurotoxicity in safety assessment (Claudio L et al. 2000, Eriksson P. 1997 \& Tilson HA. 1995), only very few of the mixture commercial chemicals in current use have been examined with respect to neurodevelopmental effects (Grandjean P \& Landrigan PJ, 2006). The use of mixture of OPIs raises the possibility of antagonistic, additive, or synergistic neurotoxicity in exposed organisms. Few studies have begun to characterize the toxicological effects of pesticides mixture exposure (Richardson et al., 2001; Schuler et al., 2005; Moser et al., 2006). On the other hand mixing organophosphate insecticides, dimethoate and methidathion (PM), becomes very common among the farmers in Yemen during growing Qat (Katha Edolis Forsk). This plant (Qat) is used to be chewed daily by people in the society including pregnant women and result in an increase in the prevalence of mixed neurodevelopmental toxicity. Recent evidence on direct roles of acetylcholinesterase (AChE) on neuronal development provides additional needs for investigating the developmental toxicity of OPIs. Therefore, the effect of the PM on the AChE of the developing chick embryo was studied by an in vivo approach. Chick embryo model has being preferably used in recent work for studies of developmental neurotoxicity of organophosphates as well as other neurotoxicants (Yanai J et al., 2004 \& 2008). Studies in mammalian models incorporate both direct and indirect neurodevelopmental effects. The indirect effects are mediated through maternal physiology and maternal/neonatal interactions. With chick embryo, we can administer PM directly to the medium surrounding the embryo without maternal mediation, eliminating the variables related to maternal physiology. In this study the effects of PM examined in an avian model, which does not share these potential confounds. From literature review lot of studies concerned the acute effect of organophosphorous insecticides on the AChE during embryo development, but this study concerned the chronic effect of PM on the AChE of developmental embryo.

\section{MATERIALS AND METHODS}

Fresh fertile chicken eggs (Gallus gallus domesticus) were used. The eggs were cleaned and placed in a commercial incubator at $37 \pm 1 \mathrm{C}^{\circ}$ and $60-65 \%$ $\mathrm{RH}$, and embryonic survival was monitored via candling. An injection window was prepared by drilling a hole in the pointed end and injection of $100 \mu \mathrm{l}$ of PM or normal saline was performed by $100 \mu \mathrm{l}$ micropipette in to the air sac. The lethal concentration for $50 \%$ killing $\left(\mathrm{LD}_{50}\right)$ values was computed based on probit analysis, (Finney, 1964) and was found to be $40 \mathrm{ppm}$. The doses $1 / 10^{\text {th }}$ $\mathrm{LD}_{50} \& 1 / 5^{\text {th }} \mathrm{LD}_{50}$ of PM (4 ppm and 8 $\mathrm{ppm}$, respectively) were chosen to be the 
tested doses. 30 fresh fertile eggs weighing $54 \pm 1$ gm were separated in to 3 batches, each batch contain 10 eggs. One batch of embryos was injected with normal saline. The other batches of embryos injected with 4 or 8 ppm PM each alternative day, starting from the day 7 of incubation for 2 weeks. The injection hole was sealed with plastic tap after each injection. On day 21 after 12 hours of the last dose an amount of 200 $\mu \mathrm{l}$ blood was collected from the blood vessels surrounding the embryonic membranes and the heamolyzate was used for the assessment of the enzyme activity calorimetrically, (Sadasivam \& Manickam 1996).

\section{Statistical method:}

Statistical analysis was performed with the aid of the Graph Pad software package. Values are presented as means \pm standard error of means (SEM). Student " $\mathrm{t}$ " test used for the analyzing of the data.

\section{RESULTS AND DISCUSSION}

The systemic toxicity of OPIs reflects the symptoms related to cholinergic hyperstimulation consequent to the irreversible loss of AChE catalytic activity, which typically emerges when inhibition exceeds 70\% (Clegg and van Gemert 1999). Result of this study indicate that repeated exposure of embryo to $1 / 10^{\text {th }}$ of the $\mathrm{LD}_{50}(4 \mathrm{ppm})$ of PM inhibited the activity of the embryo blood AChE by (40.6\%), well below the $70 \%$ threshold for the emergence of any symptoms of irreversible recovery of the AChE activity (Clegg and van Gemert 1999). And $1 / 5^{\text {th }}$ of the $\mathrm{LD}_{50}$ (8 ppm) inhibited embryo blood AChE by 69\%, which is about the threshold of irreversible recovery of the AChE activity, (Table 1). The results indicate that $1 / 10^{\text {th }}$ of the $\mathrm{LD}_{50}$ had only marginal effects of AChE inhibition, whereas $1 / 5^{\text {th }}$ of the $\mathrm{LD}_{50}$ of PM caused significant inhibition of AChE (69\%) which could not be reversible and may associate with prolonged behavioral changes and memory impairment, (Hong Zhu et al. 2001).

Table 1: Effect of pesticides mixture ( PM ) on the Acetylechlinestrase activity in chick embryo (U/ L).

\begin{tabular}{|l|c|c|c|}
\hline Dose $(\mathrm{ppm})$ & Control & Treated & P value \\
\hline 4 & \multirow{3}{*}{$561.61 \pm 42.62$} & $334.45 \pm 1.8$ & $<0.05 *$ \\
\cline { 3 - 4 } 8 & & $173.112 \pm 2.1$ & $<0.05 *$ \\
\hline
\end{tabular}

Values are expressed as mean \pm SEM $(n=10)$, Student ' $t$ ' test.

*p value is significantly different from control

The result of this study is in consistent with other studies; Miwa Misawa et al. 1981, reported that injection of diazinon on day 3 of incubation inhibited AChE of chick embryo at the age of day 6 and day 8 . Slotkin et al. 2006b and Song et al. 1997, reported that treatment of neonatal rats with $1 \mathrm{mg} / \mathrm{kg}$ chloropyrifos produced 10 $20 \%$ of AChE inhibition. Hughes et al. 1997, also reported the drastic inhibition of carp AChE activity after 5 hours exposure to $2 \mathrm{ppm}$ methidathion which associated with muscular and neural disturbances. Amina et al., 2006 and Mohan Snigh et al. 2006, reported that dimethoate separately inhibited AChE activities in maternal and fetal brain. Considering all the functions of AChE, we must ask whether PM might harm developing embryos by hindering the architectural development of their nervous systems. This would be rather speculative, especially when it involved 
the risk of low level of AChE inhibition by PM at the dose of $4 \mathrm{ppm}$. As AChE has extra-synaptic, non-cholinergic role, morphogenic role, and has a cell adhesive function during neural development, (Layer 1995, Massoulie et al. 1991 and Robertson 1993). Therefore as consequences of the AChE inhibition by $\mathrm{PM}$, it could interfere with the morphogenic function of AChE. This has effect on the neural development and axial skeletal defects in addition to behavioral changes such as embryonic convulsive and uncoordinated movements (Peddrick Weis and Judith S. Weis, 1975 \& Meneely and Wyttenbach, 2005). David and Louis, 1984 reported the inhibition of brain AChE of chick embryo treated with the organophosphorus insecticide EPN associated with cervical and axial scoliosis as well as severe edema. Similar results were reported by (Siddiqui et al. 1991 \& Zahran et al. 2005) on animals treated with OPIs. In vitro studies employing a variety of neuronal cell types have reported retardation of neurite outgrowth in response to AChE inhibition in chick embryo, (Layer et al. 1993). As the cholinergic system is involved in the growth of the axial length of the eye, (Young FA., 1965 and Stone RA et al., 1991), inhibition of AChE during embryo developmental process may result in ocular developmental defects. Previous work on other organophosphate insecticides such as chloropyrifos showed that dosing of chick embryo with chloropyrifos from day 2 to day 9 of incubation yielded an inhibition of $45 \%$ acetylcholinesterase in brain. This is resulted in a significant degree of myopia in form-deprived eyes resulting from significant lengthening of the vitrial chamber of the eye, (Andrew M. Geller et al. 1998). AChE also occurs in migrating neural crest cells (Miki et al., 1983) and inhibition of AChE by PM during early embryo development will definitely lead to a defect on the neural tube and on the CNS development. Moreover inhibition of AChE by PM may interfere with fetal developmental process that are largely dependent on the AChE ability to hydrolyze ACh (Soreq and Seidman 2001), such as neural outgrowth (Bigbee et al. 2000), synaptogenesis (Sternfeld et al. 1998), cell adhesion (Bigbee and Sharma 2004), and neuronal migration (Byers et al. 2005 \& Dori et al. 2005). Indeed, the inhibition of fetal AChE may be deleterious to coordinate development of the CNS given the postulated novel role for the AChE in nervous system development (Lassiter et al., 1998). Acetylcholine is released in response to nerve stimulation and binds to postsynaptic acetylcholine receptors, resulting in muscle contraction or gland secretions. Its action is rapidly terminated by hydrolysis with AChE via the serine hydroxyl in the catalytic triad of AChE, (Koelle GB, 1946). So the indirect effect of PM exert in its ability to induce toxicity through the inhibition of AChE, leading to accumulation of acetylcholine and subsequent activation of cholinergic, muscarinic, and nicotinic receptors (Bagchi et al., 1995). Accumulation of acetylcholine due to inhibition of AChE by PM may induce bradycardia, which is a common effect of acetylcholinesterase inhibitors, (Lin et al., 2007). However, the neuro toxicity of dimethoate seperatly depends on mixed function oxidase (MFO) catalyzed activation to its corresponding oxygen analog, which is direct inhibitor of AChE (Maroni et al., 2000). Therefore, PM may exert its effects through electrophilic attack on the cellular constituents of the developing tissues (Samanta and Chainy, 1995) with simultaneous generation of reactive oxygen species (Lemaire et al., 1994; Sharma et al., 2005). On the other hand, inhibition of AChE by PM may affect the antioxidant enzyme system which accelerate the developmental toxicity of PM, (Olga L'opez et al., 
2007). Mohamed Abou-Donia 2003, reported extensive neuropathological alterations and neurological deficits of the CNS accompanied by sever inhibition of AChE due to exposure of human to sarine.

\section{CONCLUSION}

This study illustrates that chick embryo represents a promising model system for evaluation of developmental neurotoxicity of organophosphate insecticides. The chronic exposure of chick embryo to low doses of PM induced inhibition of AChE activity. Due to the nonenzymatic functions of AChE during critical embryo CNS development PM may disturb the neuro-development so memory impairment and behavioral changes may prolong throughout the life span of the organism.

\section{REFERENCES}

Andrew M. Getter, Ali A. Abdel-Rahman, Robert L Peiffer, Mohamed B. AbouDonia and William K. Boyes. (1998). The organophosphate pesticide chloropyrifos affect forms deprivation myopia, IOVS 39 (7): 1290 - 1294.

Amina T. Farag, Tarek Abdel-Zaher Karkour, and Ahmed El Okazy. (2006). Developmental toxicity of orally administered technical dimethoate in rats. Birth Defects Research (Part B), 77:40-46.

Bagchi D, Bagchi M, Hassoun E A, Stohs S. J. (1995). In vitro and in vivo generation of reactive oxygen species, DNA damage and lactate dehydrogenase leakage by selected pesticides. Toxicology, 104:129-140.

Bigbee JW, Sharma KV, Chan ELP, Bogler O. (2000). Evidence for the direct role of acetylcholinesterase in neurite outgrowth in primary dorsal root ganglionn. Brain Res. 861:354-362.

Bigbee J.W.; Sharma, K.V. (2004). The adhesive role of acetylcholinesterase (AChE): detection of AChE binding proteins in developing rat spinal cord. Neurochem Res. 29(11):2043-2050.

Byers DM, Irwin LN, Moss DE, Sumaya IC, Hohmann CF. (2005). Prenatal exposure to the acetylcholinesterase inhibitor methanesulfonyl fluoride alters forebrain morphology and gene expression. Dev Brain Res. 158 (1-2):13-22.

Claudio L, Kwa WC, Russell AL, Wallinga D. (2000). Testing methods for developmental neurotoxicity of environmental chemicals. Toxic Pharmacol. 164:1-14.

Clegg DJ, van Gemert M. (1999). Determination of the reference dose for chlorpyrifos: proceedings of an expert panel. J Toxicol Environ Health, 2:211255.

Colborn T. (2006). A case for revisiting the safety of pesticides: a closer look at neurodevelopment. Environ Health Perspect. 114:10-17.

Cosenza M E, Bidanet J. (1995). Effects of chlorpyrifos on neuronal development in rat embryo midbrain micromass cultures. Vet Human Toxicol. 37:118-121.

Costa LG. (2006). Current issues in organophosphate toxicology. Clin Chim Acta. 366:1-13.

Crumpton TL, Seidler FJ, Slotkin TA. (2000). Developmental neurotoxicity of chlorpyrifos in vivo and in vitro: effects on nuclear transcription factor involved in cell replication and differentiation. Brain Res., 857: 87-98.

Das KP, Barone S. (1999). Neuronal differentiation in PC12 cells is inhibited by chlorpyrifos and its metabolites: is acetylcholinesterase inhibition the site of action? Toxicol Appl Pharmacol. 160: 217-230.

David J. Hoffman and Louis Sileo. (1984). Neurotoxic and teratogenic effects of an organophosphorus insecticide (phenyl phosphonothioic acid-O-ethyl-O-[4nitrophenyl] ester) on mallard development, Toxicology and Applied Pharmacology, 73(2): 284-294.

De Peyster A, Willis WO, Molgaard CA, MacKendrick TM, Walker C. (1993). Cholinesterase and self-reported pesticide exposure among pregnant women. Arch Environ Health, 48: 348-352.

Dori A, Cohen J, Silverman WF, Pollack Y, Soreq H. (2005). Functional manipulations of acetylcholinesterase splice variants highlight alternative splicing contributions to 
murine development. Cereb Cortex, 15 (4): 419-430.

Eriksson P: (1997). Developmental neurotoxicity of environmental agents in the neonate. Neurotoxicology, 18: 719-726.

Finney, D. J. (1971). Probit analysis, 2 edition (Cambridge: University Press), 1964.

Fukuto, T. R. Bull. W.H.O., 44: 31-.

Gallo, M.A. and Lawryk, N.J. Organic phosphorus pesticides. In: W.J. Hayes and E.R. (1991). Laws (eds), "Handbook of pesticide toxicology", pp.917-1123. Academic Press, San Diego,California, USA.

Grandjean P, Landrigan PJ. (2006). Developmental neurotoxicity of industrial chemicals. Lancet, 368:21672178.

Gurunathan S, Robson M, Freeman N, (1998). Buckley B, Roy A, Meyer R. Accumulation of chlorpyrifos on residential surfaces and toys accessible to children, Environ Health Perspect. 106:9-16.

Hong Zhu, Robin W. Rockhold, Rodney C. Baker, Robert E. Kramer, Ing K. Ho. (2001). Effects of single or repeated dermal exposure to methyl parathion on behavior and blood cholinesterase activity in rats. Journal of Biomedical Science, 8:467-474.

Hughes GM, Szegletes T, Nemcs k J. (1997). Study of the effects of brief exposure to an organophosphorous insecticide (methidathion) on blood characteristics of carp (Cyprinus carpio). Acta Biol Hung. 48(2):157-66.

Jameson RR, Seidler FJ, Qiao D, Slotkin TA. (2006). Chlorpyrifos affects phenotypic outcomes in a model of mammalian neurodevelopment: critical stages targeting differentiation in PC12 cells. Environ Health Perspect., 114:667-672.

Koelle GB. (1946). Protection of cholinesterase against inevitable inactivation by diisopropyl fluorophosphate in vitro. J Pharmacol Exp Ther. 88:232-37.

Landrigan PJ, Claudio L, Markowitz SB, Berkowitz GS, Brenner BL, Romero H, Wetmur JG, Matte TD, Gore AC, Godbold JH. (1999). Pesticides and inner-city children: exposures, risks, and prevention. Environ Health Perspect. 107(suppl. 3):431-437.

Lassiter TL, (1998). Padilla S, Mortensen SR, Chanada SM,Moser VC, Barone S Jr. Gestational exposure to chloropyrifos: apparent protection of the fetus? Toxicol Appl Pharmacol. 152:56-65

Layer PG, Weikert T, Alber R. (1993). Cholinesterase regulate neurite outgrowth of nerve cells in vitro by means of a non cholinergic enzymatic mechanism. Cell Tissue Res. 273: 219226.

Layer PG, Willbold E. (1995). Novel functions of cholinesterase in development, physiology and disease. Prog Histochem Cytochem. 29: 1-94.

Lemaire $\mathrm{P}$, Mathews A, Forlin L, Livingstone DR. (1994). Stimulation of oxyradical production of hepatic microsomes of flounder (Platichthys esus) and perch (Perca uviatilis) by model and pollutant xenobiotics. Arch Environ Contam Toxicol. 26:191-200.

Lin, Michelle N.Y. Hui and S.H. Cheng. (2007). Toxicity and cardiac effects of carbaryl in early developing zebrafish (Danio rerio) embryos. Toxicology and Applied Pharmacology, 222(2): 159-168.

Maroni M, Colosio C, Feridi A, Fait A. (2000). Organophosphorus pesticides. Toxicology, 143:9-37.

Masspulie J., Pezzemeti L. Bon Sb., Krejci E., Vallette FM. (1991). Molecular and cellular biology of cholinestrases. Prog Neurobiol. 41: 31-91.

Meneely, G. A. and Wyttenbach, C. R. (1989). Effects of the organophosphate insecticides diazinon and parathion on bobwhite quail embryos: Skeletal defects and acetylcholinesterase activity. Journal of Experimental Zoology, 252 (1): 6070.

Miwa Misawa, John Doull, Paul A. Kitos and Edwin M. Uyeki. (1981). Teratogenic effects of cholinergic insecticides in chick embryos I. Diazinon treatment on acetylcholinesterase and choline acetyltransferase activities. Toxicology and Applied Pharmacology 57(1): 20-29.

Miki, A., Fujimoto, E., and Mizoguti, H. (1983). Acetylcholinesterase activity in neural crest cells of the early chick embryo. Histochemistry, 78:81-93. 
M.M. Zahran, K.B. Abdel-Aziz, A. AbdelRaof and E.M. Nahas. The (2005). Effect of subacute doses of organophosphorus pesticide, nuvacron, on the biochemical and cytogenetic parameters of mice and their embryos. Research Journal of Agriculture and Biological Sciences, 1(3): 277-283.

Mohamed Abou-Donia.

(2003). Organophosphorus Ester-Induced Chronic Neurotoxicity. Archives of Environmental Health, 58 (8): 484 - 497.

Mohan Snigh, Rajat Sandhir and Ravi Kiran. (2006). Erythrocyte antioxidant enzymes in toxicological evaluation of commonly used organophosphate pesticides. Indian Journal of Experimental Biology, 44:580-583.

Moser, V.C.; Simmons, J.E. and Gennings, C. (2006). Neurotoxicological interactions of a five-pesticide mixture in preweanling rats. Toxicol. Sci. 92 (1): 235-245.

Monnet-Tschudi F, Zurich MG, Schilter B, Costa LG, Honegger P. (2000). Maturation-dependent effects of chlorpyrifos and parathion and their oxygen analogs on acetylcholinesterase and neuronal and glial markers in aggregating brain cell cultures. Toxicol Appl Pharmacol.165:175-183.

Olga L'opez, Antonio F. (2007). Hernandez, Lourdes Rodrigo, Fernando Gil, Gloria Pena, Jose Luis Serrano, Tesif on Parron,, Enrique Villanueva, Antonio Pla. Changes in antioxidant enzymes in humans with long-term exposure to pesticides. Toxicology Letters, 171: 146-153.

Peddrick Weis and Judith S. (1975). Weis. Abnormal locomotion associated with skeletal malformations in the sheepshead minnow, Cyprinodon variegatus, exposed to malathion. Environmental Research, 12(2): 196-200.

Qiao D, Seidler FJ, Slotkin TA. (2001). Developmental neurotoxicity of chlorpyrifos modeled in vitro: comparative effects of metabolites and other cholinesterase inhibitors on DNA synthesis in PC12 and C6 cells. Environ Health Perspect. 109: 909-913.

Qiao D, Seidler FJ, Slotkin TA. (2005). Oxidative mechanisms contributing to the developmental neurotoxicity of nicotine and chlorpyrifos. Toxicol Appl Pharmacol. 206: 17-26.

Rauh VA, Garfinkel R, Perera FP, Andrews HF, Hoepner L, Barr DB. (2006). Impact of prenatal chlorpyrifos exposure on neurodevelopment in the first 3 years of life among inner-city children. Pediatrics, 118:1845-1859.

Richardson, J.R.; Chambers, H.W. and Chamders, J.E. (2001). Analysis of the additivity of in vitro inhibition of cholinesterase by a mixture of chlorpryifos-oxon and azinphos-methyloxon. Toxicol Appl Pharmacol. 172: 128-139.

Robertson RT, Yu J. (1993). Acetylcholinestrase and neural development: new tricks for an old dog. News Physiol Sci. 8: 266-272,.

Rohlman DS, Arcury TA, Quandt SA, Lasarev M, Rothlein J, Travers R. (2005). Neurobehavioral performance in preschool children from agricultural and non-agricultural communities in Oregon and North Carolina. Neurotoxicology, 26 (4) :589-598.

Samanta L, Chainy GB. (1995). Hexachlorocyclohexane-induced changes in lipid peroxidation, superoxide dismutase and catalase activities and glutathione content in chick liver. Indian J Exp Biol. 33: 131-133.

Schuler, L.J.; Trimble, A.J.; Belden, J.B. and Lydy, M.J. (2005). Joint toxicity of triazine herbicides and organophosphate insecticides to the midge Chironomus tentans. Arch Environ. Contam. Toxicol. 49 (2):173-177.

Sharmaa Y, Somia BM, Irshad B, Datta G, Dograa TD. (2005). Effects of acute dimethoate administration on antioxidant status of liver and brain of experimental rats. Toxicology, 206:49-57.

Siddiqui, M.K., M.F. Rahman and M. Mustafa. (1991). A comparative study of blood changes and brain acetycholinesterase inhibition by monocrotophos and its analogues in rats. Ecotoxicology and Environmental Safety, 21:283-289.

Slotkin TA, MacKillop EA, Ryde IT, Tate CA, Seidler FJ. (2007). Screening for developmental neurotoxicity using PC12 cells: comparisons of organophosphates 
with a carbamate, an organochlorine and divalent nickel. Environ Health Perspect. 115:93-101.

Song X, Violin J D, Seidler F J, Slotkin T A. (1998). Modeling the developmental neurotoxicity of chlorpyrifos in vitro: macromolecule synthesis in PC12 cells. Toxicol Appl Pharmacol. 151:182-191.

Soreq H, Seidman S. (2001). Acetylcholinesterase: new roles for an old actor. Nat Rev Neurosci. 2 (4): 294-302.

S. Sadasivam and A. Manickam (1996). Biochemical method, second edition, new age international (P) limited publishers.

Sternfeld M, Ming GL, Song HJ, Sela K, (1998). Timberg R. Acetylcholinesterase enhances neurite growth and synapse development through alternative contributions of its hydrolytic capacity. J Neurosci. 18:1240-1249.

Stone R A, Lin T, Laties A M. (1991). Muscarinic antagonist effects on experimental chick myopia. Exp Eye Res. 52:755-758.
Tilson, H A. (1995) The concern for developmental neurotoxicology: is it justified and what is being done about it? Environ Health Perspect. 103 (Suppl 6):147-151.

Weiss B, Amler S, Amler RW. (2004). Pesticides. Pediatrics, 113:1030-1036.

Yanai J, Beer A, Huleihel R, Izrael M, Katz S, Levi Y, Rozenboim I, Yaniv SP, Slotkin TA. (2004). Convergent effects on cell signaling mechanisms mediate the actions of different neurobehavioral teratogens: alterations in cholinergic regulation of PKC in chick and avian models. Ann NY Acad Sci. 1025: 595-601.

Yanai J, Dotan S, Goz R, Pinkas A, Seidler FJ, Zimmerman FS, Slotkin TA. (2008). Exposure of developing chicks to perfluorooctanoic acid induces defects in prehatch and early posthatch development. J Toxicol Environ Health, 71:131-133.

Young FA. (1965). The effect of atropine on the development of myopia in monkeys. AmJ Optom Arch Am Acad Optom. 42:439 -449. 